\title{
Adsorptive Stripping Voltammetric Determination of Oxolinic Acid in Water Sample
}

\author{
Herbert Aleixo, * Leonardo L. Okumura, Astréa F. S. Silva, Alexandre Gurgel and \\ Juliana A. Diniz.
}

Departamento de Química, Universidade Federal de Viçosa, 36570-900 Viçosa-MG, Brazil

\begin{abstract}
One new methodology for analysis of the antimicrobial oxolinic acid (OXA) based on adsorptive stripping voltammetry (AdSV) in carbon paste electrode (CPE) was developed and applied in untreated pond water sample. Cyclic voltammetry (CV) indicated that an irreversible anodic process occurs in $\mathrm{KOH}$ solution as supporting electrolyte. Quantification of the antimicrobial was carried out by differential pulse adsorptive stripping voltammetry (DPAdSV) at potential of deposition $\left(\mathrm{E}_{\mathrm{D}}\right)+1.05 \mathrm{~V}$ for $45 \mathrm{~s}$ to examine OXA adsorption on the surface of CPE. The limits of detection (LOD) and quantification (LOQ) of the method for OXA analysis were determined. The values of LOD were 0.0570 and $0.512 \mathrm{mg} \mathrm{L}^{-1}$ in absence of matrix and in the water sample, respectively, and the corresponding values of LOQ were 0.192 and $1.707 \mathrm{mg} \mathrm{L}^{-1}$, respectively. The apparent recovery percentage for different concentrations of OXA in natural waters ranged between 98.4 and $109 \%$.
\end{abstract}

Keywords: antimicrobial, quinolone, adsorptive stripping voltammetry, carbon paste electrode

\section{Introduction}

Water is essential for life and must be available in a safe, sustainable way. The development of strategies for the rational use of water resources and novel methodologies to monitor their quality are indispensable so that availability is not supplanted by the demand for water.

Animal production is one of the most expressive activities in the Brazilian agribusiness. The use of medicaments with therapeutic or prophylactic purposes is widely applied to ensure the productivity and competitiveness of the sector, by means of which better-quality food has certainly been produced. ${ }^{1}$ Most veterinary medicaments are administered as feed additives or added to water to prevent disease or improve animal growth. ${ }^{2}$ The use of these substances in the treatment of intensive livestock (cattle, pigs and poultry) and in aquaculture represents the main route of entry of antimicrobials into the environment and may lead to the contamination of aquatic and terrestrial environments. ${ }^{3}$ They can enter the environment as isolated compounds or metabolites, conjugates, or both. ${ }^{4}$

Contamination of the environment can occur by the use of animal manure and effluent treatment sludge containing veterinary drug residues as fertilizer. Other sources of

*e-mail: herbertaleixo@gmail.com contamination include waste treatment lagoons improperly constructed, which the contaminants may be leaked or leached from waste into surface water and groundwater. In addition, antimicrobials are applied directly to surface waters for aquaculture, and may accumulate large amounts of residues of these compounds, altering the aquatic ecosystem. ${ }^{5}$

Among the most commonly used veterinary medicaments, antimicrobial agents comprise some of the most prescribed classes. ${ }^{6}$ Its indiscriminate use entails serious damage to the environment and human health, as allergic reactions to the active principles and to lead to antimicrobial resistance in both human and animal intestinal bacteria, as well as in common environmental bacteria. $^{7}$

Quinolones and fluoroquinolones are heterocyclic antimicrobial compounds with high biological and pharmacological activities. ${ }^{8}$ This antimicrobials agents are fairly tolerable to humans and can be widely used against mycobaterial and anaerobic organisms, acting by the inhibition of bacterial enzymes DNA gyrase and topoisomerase IV. ${ }^{9}$ The first antibiotic agent of the quinolone class was synthesized in the laboratory in the 1960s by obtaining nalidixic acid as a by-product synthesis of antimalarial compounds synthesis. ${ }^{10}$ Since then, structural modifications have resulted in the second, third and fourth generations of quinolones and fluoroquinolones, which 
are effective against Gram-negative and Gram-positive bacteria, being more powerful and featuring a wide activity spectrum. ${ }^{11}$ Such compounds can be successfully used in the treatment of some human diseases ${ }^{12,13}$ and widely employed in the composition of veterinary medicaments. ${ }^{14-16}$

Oxolinic acid (OXA), i.e., 5-ethyl-8-oxo-5,8-dihydro [1,3]dioxolo[4,5-g]-quinoline-7-carboxylic acid (Figure 1), is a wide-spectrum antimicrobial drug of the first generation of quinolones that is applied in the treatment of diseases caused by Gram-negative bacteria. ${ }^{17}$ Although forbidden in some countries where it is replaced with more efficient fluoroquinolones, OXA is still used in the treatment of infections of the digestive and urinary systems caused by Salmonella ${ }^{18}$ and also widely applied as a veterinary agent, being monitored in Brazil in cattle, pigs, horses, hens, milk, eggs and fish. ${ }^{19}$

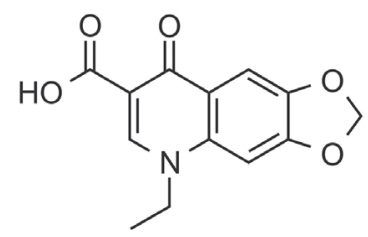

Figure 1. Molecular structure of oxolinic acid (OXA).

Several analytical methods have been developed to determine OXA in different matrices. Among all methods, those involving chromatography are more commonly used, and gas chromatography can be particularly employed in the detection of quinolones, like OXA in fish. ${ }^{20,21}$ Other applications focus on the derivatization of the analyte by liquid chromatography and detection by luminescence. ${ }^{22,23}$

Ultra-high-performance liquid chromatography has also been used to simultaneously detect OXA and other quinolones in meat ${ }^{24}$ and fish ${ }^{25}$ samples. The liquid chromatography coupled to mass spectrometry technique was used to determine quinolones in poultry muscle and kidneys. ${ }^{26}$ Besides several researches focusing on the analyses of animal samples, liquid chromatography can also be potentially used in the monitoring of antibiotics in water samples. ${ }^{27,28}$ Other methods which do not involve chromatography, such as those based on electrophoretic ${ }^{29,30}$ and spectrofluorometric ${ }^{31}$ techniques, have been suggested as alternatives in the analyses of such compounds. Although a considerable amount of reports propose different methodologies to determine OXA, no reports on the use of voltammetric techniques to determine this quinolone have been found.

Recently, voltammetric techniques have been proposed as viable alternatives to chromatography to analyze various contaminants, due to low cost and possibility of using portable equipment for in loco assays. Moreover, analyses with colored solutions or systems containing suspended particulate matter can be carried out, which enables the direct use of matrices in the measurements. This would be unviable with chromatography. As a result, voltammetric techniques which are rapid, sensitive, precise and reproducible have been devised, with the additional advantage of low consumption of chemicals, normally dispensing with complex steps involving extraction or previous treatment of samples. ${ }^{32}$ Because several veterinary medicaments are inadequately used or discharged, and the quality of natural water sources must be monitored quicker with lower costs, the main objective of this work was to develop a novel voltammetric methodology to determine and quantify the OXA antibiotic in untreated water samples.

\section{Experimental}

\section{Electrochemical apparatus and chemicals}

Analytical-grade chemicals submitted to no previous purification step have been used in this work. Oxolinic acid (OXA) and potassium hydroxide were purchased from Sigma-Aldrich (Fluka, analytical standards, Belgium). During some initial experiments, absolute ethyl alcohol (analytical standard) and two buffer solutions, prepared with ethanoic acid (99.7\%), boric acid (99.5\%), phosphoric acid (> 85\%) and potassium carbonate $(99.0 \%)$, have been used. These chemicals were purchased from Vetec (Brazil).

All voltammetric measurements were carried out in a PGSTAT $128 \mathrm{~N}$ Autolab potentiostat/galvanostat (Eco-Chemie, Utrecht, The Netherlands) interfaced to a computer by the GPES software (version 4.9), using a $50 \mathrm{~mL}$ conventional electrochemical cell stoppered with a Teflon ${ }^{\circledR}$ lid and equipped with a three-electrode assembly, namely the $\mathrm{Ag} \mid \mathrm{AgCl}, \mathrm{KCl} 3.0 \mathrm{~mol} \mathrm{~L}^{-1}$ reference electrode, a platinum wire as auxiliary electrode, and a carbon paste electrode (CPE) as work electrode, with a geometrical surface area of $0.283 \mathrm{~cm}^{2}$. All electrodes were purchased from Metrohm (Switzerland).

\section{Stock solution of OXA}

Prior to the preparation of the stock solution, solubility assays were carried out in two Eppendorf ${ }^{\oplus}$ vials to visually compare the capacity of pure ethanol and $0.100 \mathrm{~mol} \mathrm{~L}^{-1}$ $\mathrm{KOH}$ aqueous solution to dissolve $1.000 \mathrm{mg}$ of OXA. Based on this initial test, the stock solution of the antibiotic was then prepared in $50.00 \mathrm{~mL}$ of $0.100 \mathrm{~mol} \mathrm{~L}^{-1} \mathrm{KOH}$ aqueous solution, to obtain a final OXA concentration of $1.000 \mathrm{~g} \mathrm{~L}^{-1}\left(38.30 \mathrm{mmol} \mathrm{L}^{-1}\right)$. This OXA stock solution and all other previously prepared solutions which constitute 
the supporting electrolyte were kept under refrigeration (below $10^{\circ} \mathrm{C}$ ). Diluted analyte solutions were prepared by transferring aliquots of the stock solution to a conventional voltammetric cell and subsequent diluting them to a final volume of $10.00 \mathrm{~mL}$. Deionized water with resistivity lower than $18.2 \mathrm{M} \Omega \mathrm{cm}$ (Milli-Q System, Millipore, USA) was always used in this procedure.

\section{Carbon paste electrode}

Carbon paste was prepared by mixing graphite powder (Merck, Germany) and mineral oil (Acros Organic, Belgium) in appropriate amounts. The mixtures obtained with each proportion were dispersed in $n$-hexane (SigmaAldrich, USA) and stirred for approximately $2 \mathrm{~h}$ on a Corning PC-420D magnetic plate until complete solvent evaporation. The carbon paste was then dried at room temperature $\left(25 \pm 1{ }^{\circ} \mathrm{C}\right)$, after which it was inserted in the electrode with care to avoid empty spaces in order to obtain a homogeneous surface. After each voltammetric measurement, the electrode surface was renewed by removing an outer layer and packing another proper amount of carbon paste.

\section{Water samples}

The technique was applied with non-potable, nontreated water samples collected from lakes and ponds existing in the campus of Federal University of Viçosa (UFV, Brazil). Some of these water bodies act as reservoirs of the São Bartolomeu stream and supply water to the UFV campus and a large part of Viçosa City, in the Brazilian state of Minas Gerais. Sample collection was performed at approximately $30 \mathrm{~cm}$ from the surface and stored under refrigeration in glass bottles until the analyses. The samples were not subjected to any purification process prior to their analyses.

\section{Electrochemical detection of OXA}

Three voltammetric techniques were applied to detect OXA, namely cyclic voltammetry (CV), differential-pulse voltammetry (DPV) and square-wave voltammetry (SWV). The CV technique was employed to characterize electrodic processes with the antibiotic, whilst DPV and SWV were applied to quantify the amounts of analyte with more precision and sensitivity. All measurements were made at room temperature $\left(25 \pm 1{ }^{\circ} \mathrm{C}\right)$ and at least in triplicate.

Due to the absence of previous reports focusing on the voltammetric detection of OXA, an initial investigation was carried out on the electroactivity of the compound and the supporting electrolyte, as well as the $\mathrm{pH}$ at which the redox phenomenon is favored. After selection of the best instrumental parameters and the most sensitive electroanalytic technique, an analytical curve was constructed upon addition of aliquots of the OXA stock solution (within a final concentration range between 0.500 and $40.0 \mathrm{mg} \mathrm{L}^{-1}$ ) to the electrochemical cell containing the supporting electrolyte. By determining the intensities of the peak current as a function of the variation of OXA concentration, linear regression of the data was performed with the method of least squares. Different situations were examined with this method: (i) addition of a standard solution in deionized water and (ii) addition of a standard solution in the presence of a non-potable water matrix. The method was also validated by repeatability, reproducibility and apparent-recovery assays directly with the actual water samples. For this investigation, solutions were prepared by adding proper volumes of the OXA stock solution and the supporting electrolyte to $9.00 \mathrm{~mL}$ of water from the lake, to reach a total of $10.00 \mathrm{~mL}$ for analysis.

\section{Results and Discussion}

\section{Voltammetric behavior of OXA}

Cyclic voltammetry (CV) was employed to characterize possible oxirreduction processes of the analyte. The first voltammetric study of OXA was carried out with a positive electric potential ranging between 0.0 and $+1.7 \mathrm{~V} v s . \mathrm{Ag} \mid \mathrm{AgCl}, \mathrm{KCl} 3 \mathrm{~mol} \mathrm{~L}^{-1}$ in a $0.100 \mathrm{~mol} \mathrm{~L}^{-1} \mathrm{KOH}$ solution as supporting electrolyte. The work electrode was $\mathrm{CPE}$, prepared by mixing graphite powder and mineral oil at a mass proportion of 70:30 $(\% \mathrm{~m} / \mathrm{m})$.

Figure 2A shows an anodic peak at approximately $+1.15 \mathrm{~V} v s . \mathrm{Ag} \mid \mathrm{AgCl}, \mathrm{KCl} 3 \mathrm{~mol} \mathrm{~L}^{-1}\left(\mathrm{E}_{\mathrm{pa}}\right)$ at a scan rate rate of $100 \mathrm{mV} \mathrm{s}^{-1}$. The absence of a cathodic peak in the reversed scan suggests the occurrence of an irreversible oxidation process or the existence of coupled chemical reactions in the sequence of the electrode process.

When carried out within a negative-potential interval, cyclic voltammetry did not show any reduction or oxidation peak for the experimental conditions employed in this study. Assays for which successive CV scannings were applied without renewing the surface of the work electrode could show a gradual decrease in the intensity of the anodic peak $\left(\mathrm{I}_{\mathrm{p}}\right.$ ) after each cycle (by approximately $56 \%$ between the first and the tenth cycle), as indicated in Figure 2B. This is due to the adsorption of the OXA oxidation product on the surface of the work electrode, which reduces the current intensity at each successive peak. The adsorption of this product impairs the electrochemical 

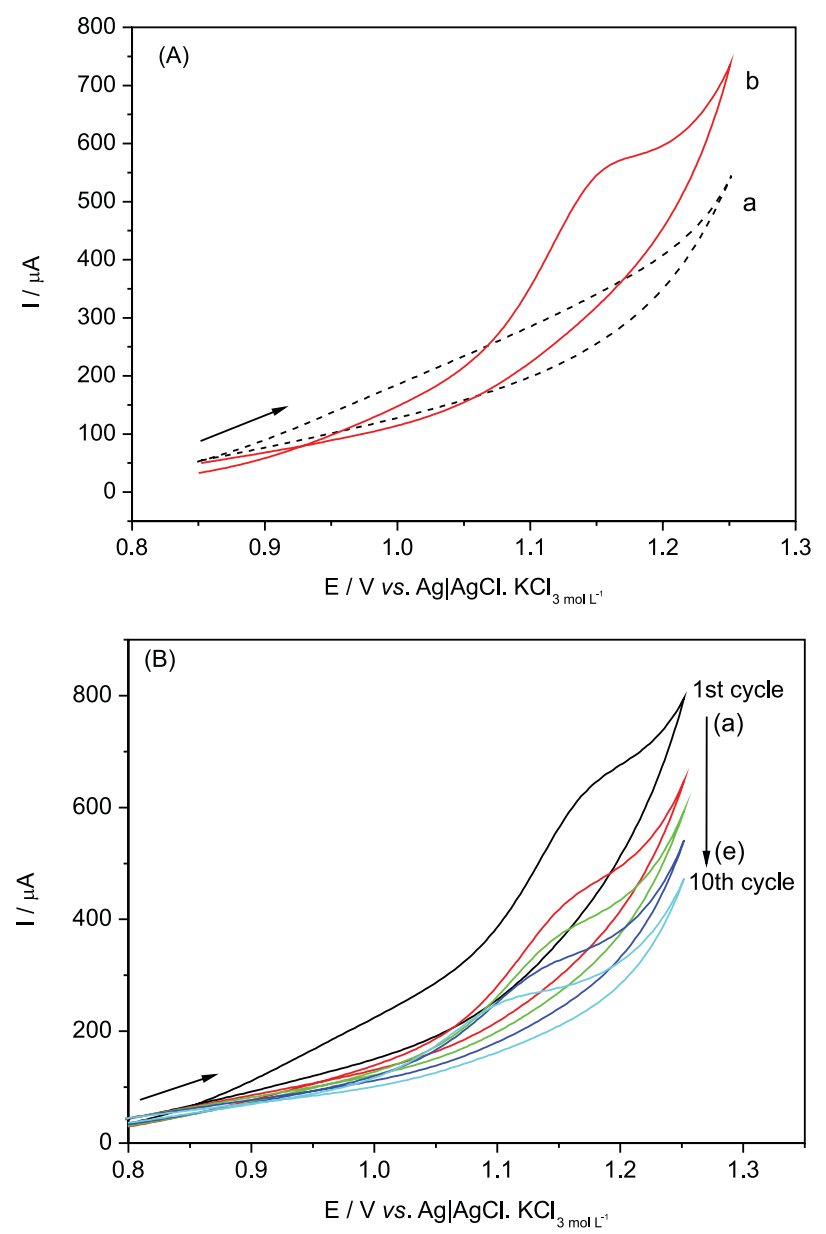

Figure 2. (A) Cyclic voltammograms of (a) blank and (b) $1.00 \mathrm{mmol} \mathrm{L}^{-1}$ OXA solution; (B) successive-cycle voltammograms in $0.100 \mathrm{~mol} \mathrm{~L}^{-1}$ $\mathrm{KOH}$ solution as supporting electrolyte and CPE: (a) $1^{\text {st }}$ cycle (b) $2^{\text {nd }}$ cycle; (c) $3^{\text {rd }}$ cycle; (d) $5^{\text {th }}$ cycle; (e) $10^{\text {th }}$ cycle $\left(v=100 \mathrm{mV} \mathrm{s}^{-1}\right)$.

cleaning of the surface of the work electrode. In view of this, renewal of the surface of the carbon paste was manually carried out prior to each voltammetric measurement.

The voltammetric behavior of OXA as a function of the scan rate of the electrical potential $(v)$ was assessed with potentials ranging between +0.5 and $+1.25 \mathrm{~V}$ with a $0.100 \mathrm{~mol} \mathrm{~L}^{-1} \mathrm{KOH}$ solution as supporting electrolyte. For the oxidation process of OXA, a linear behavior (coefficient of determination $\left(\mathrm{R}^{2}\right)=0.993$ ) was observed for the intensity of the peak current $\left(\mathrm{I}_{\mathrm{pa}}\right)$ with the square root of the scan rate of the electrical potential $\left(v^{1 / 2}\right)$, as depicted in Figure 3a. Such behavior indicates that the mass transfer anodic process is controlled by the diffusion of the compound to the surface of the work electrode. Aiming to confirm the irreversibility of the OXA oxidation process, the current function was determined for the anodic process. This function is given by the mathematical relationship between the parameter $\left(\mathrm{I}_{\mathrm{pa}} / \mathrm{v}^{1 / 2}\right)$ and the scan rate of the electrical potential $(v) .^{33}$ In Figure $3 b$, one can see that the parameter $\left(\mathrm{I}_{\mathrm{pa}} / v^{1 / 2}\right)$ is approximately constant with $v$ within the studied interval, thereby confirming an irreversible anodic process without any chemical reactions coupled to the redox system. ${ }^{34}$
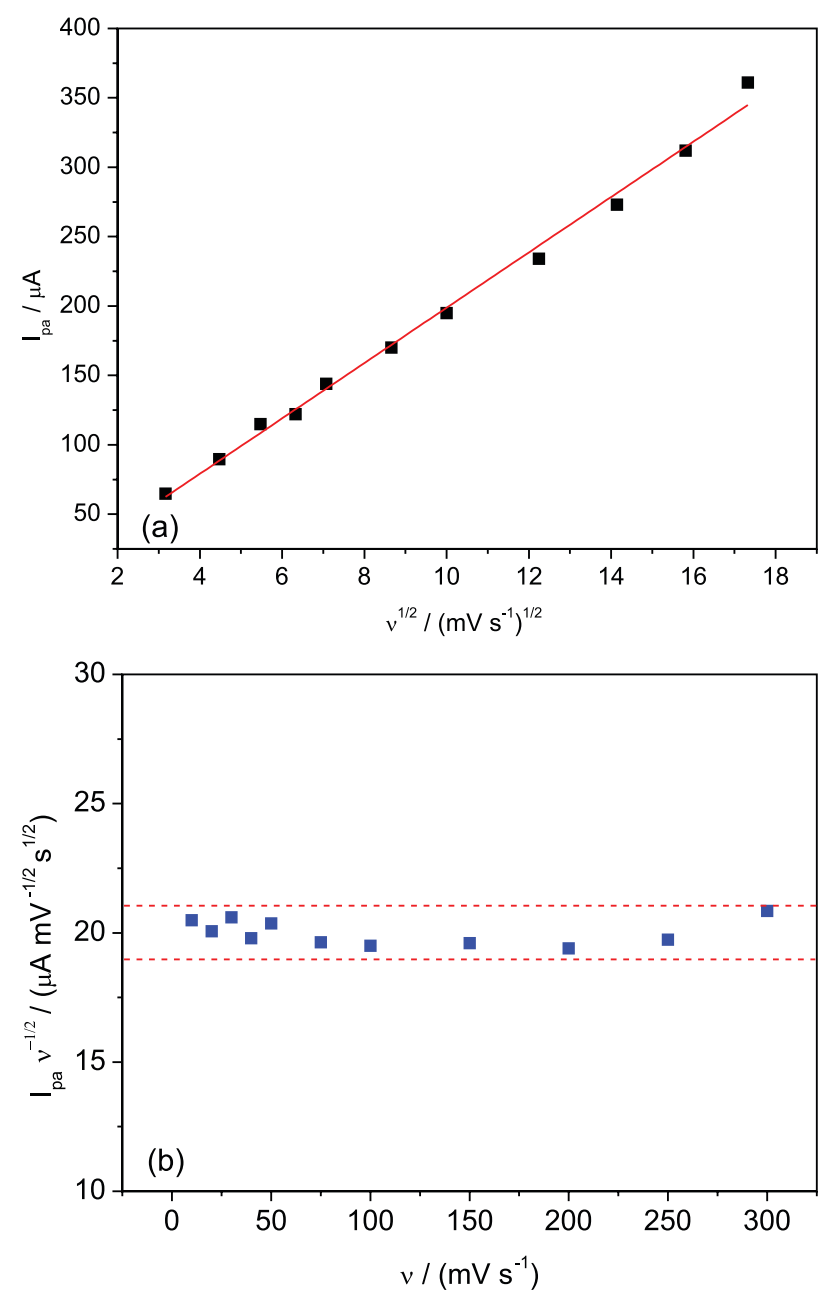

Figure 3. (a) Intensity of the anodic peak current $\left(I_{\mathrm{pa}}\right)$ as a function of the square root of the scan rate of the electrical potential $\left(v^{1 / 2}\right)$; (b) plot of the current function $\left(\mathrm{I}_{\mathrm{pa}} / \mathrm{v}^{1 / 2}\right)$ versus the scan rate of the electrical potential in $1.00 \mathrm{mmol} \mathrm{L}^{-1}$ OXA solution, $0.100 \mathrm{~mol} \mathrm{~L}^{-1} \mathrm{KOH}$ solution as supporting electrolyte and CPE. The dashed lines establish a maximal deviation of $\pm 5.0 \%$ from the mean value of the current function for all data.

Differential-pulse voltammetry (DPV) data were used to determine the number of electrons transferred in the OXA redox process on the surface of the work electrode. Equation 1 shows how the mid-height redox peak width $\left(\mathrm{W}_{1 / 2}\right)$ varies with temperature $(\mathrm{T})$ and the actual number of electrons transferred by each oxidized molecule (n). R is the gas constant and $\mathrm{F}$ is the Faraday constant. ${ }^{34}$

$\mathrm{W}_{1 / 2}=\frac{3.52 \mathrm{RT}}{\mathrm{nF}}$

With the experimental $\mathrm{W}_{1 / 2}$ value obtained with DPV for $\mathrm{T}=298 \mathrm{~K}$ in equation 1 , one has $\mathrm{n}=0.87$, which 
suggests that only one electron is transferred in the OXA oxidation process.

By analyzing the voltammetric behavior of OXA and observing that at the $\mathrm{pH}$ of the analyses the carboxylic acid group is deprotonated (OXA p $\left.K_{\mathrm{a}}=6.3\right),{ }^{35}$ the oxidation mechanism occurs first by the removal of one electron from the carboxyl group followed by the elimination of this group $\left(-\mathrm{COO}^{-}\right)$, forming a neutral radical. The combination of two of these radicals forms a stable dimer, in a process similar to the Kolbe reaction. ${ }^{36}$ Since the structure of the radical formed has delocalized electrons, different resonance structures are observed, and it is not possible to precisely propose the structure of the dimer formed by the oxidation of OXA only with these assays. Scheme 1 shows a representation of the proposed mechanism, which is similar to the oxidative behavior of methylenedioxymethamphetamine (MDMA), both by the structure and by the proximity of the peak potential of OXA and MDMA. ${ }^{37}$

$$
\begin{gathered}
\mathrm{R}-\mathrm{CO}_{2}^{-} \underset{-\mathrm{e}^{-},-\mathrm{CO}_{2}}{\longrightarrow} \mathrm{CPE} \text { in } \mathrm{H}_{2} \mathrm{O} \\
2 \mathrm{R} \bullet \\
\longrightarrow \mathrm{R}-\mathrm{R}
\end{gathered}
$$

Scheme 1. Proposed mechanism for the electrochemical oxidation of OXA in CPE.

\section{Optimization of the analytical conditions for OXA}

The voltammetric response of OXA was examined with different aqueous solutions of the supporting electrolyte by DPV. The reduction in the solubility of OXA in the aqueous solutions with $\mathrm{pH}$ lower than 9 impaired the analysis of the electrode behavior in neutral or acidic solutions. The invetigation was therefore carried out with Britton-Robinson (BR) and carbonate buffers as supporting electrolyte, both at $\mathrm{pH} 10$. Comparison of the voltammograms for the oxidation of OXA in $\mathrm{KOH}$ and in both buffers can be observed in Figure 4A. Lower peak potential $\left(\mathrm{E}_{\mathrm{pa}}\right)$ and lower mid-height peak width $\left(\mathrm{W}_{1 / 2}\right)$ are observed with the $\mathrm{KOH}$ aqueous solution. Also, a significant increase in the intensity of the peak current $\left(\mathrm{I}_{\mathrm{pa}}\right)$ is shown in Figure 4B for $\mathrm{pH}$ higher than 12. This suggests that the mechanism of OXA oxidation and the mass transfer process are directly affected by the high concentrations of $\mathrm{OH}^{-}$ions.

The best carbon paste composition was also chosen from three different proportions between grafite and binder (the mineral oil). The grafite content varied between 70 and $80 \%$ of the total produced paste. Table 1 shows the results for $\mathrm{I}_{\mathrm{pa}}, \mathrm{E}_{\mathrm{pa}}$ and $\mathrm{W}_{1 / 2}$ obtained for each prepared sample. It can be seen that the intensity of the peak current $\left(\mathrm{I}_{\mathrm{pa}}\right)$ is
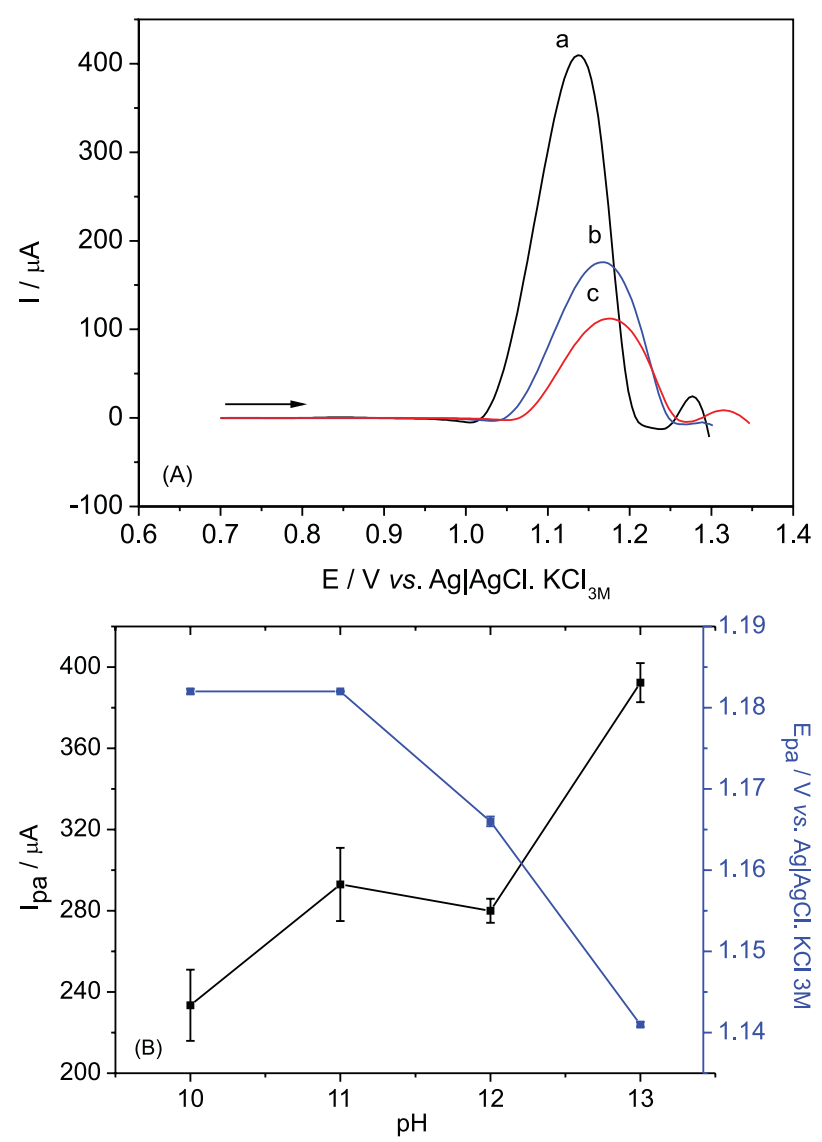

Figure 4. (A) Differential-pulse voltammograms for $1.00 \mathrm{mmol} \mathrm{L}^{-1} \mathrm{OXA}$ solutions using (a) $0.100 \mathrm{~mol} \mathrm{~L}^{-1} \mathrm{KOH}$ solution at $\mathrm{pH} 12$; (b) BR buffer at $\mathrm{pH} 10$; (c) carbonate buffer at $\mathrm{pH} \mathrm{10}$; and (B) effects of $\mathrm{pH}$ of the $\mathrm{KOH}$ solution on $\mathrm{I}_{\mathrm{pa}}$ and $\mathrm{E}_{\mathrm{pa}}$.

reduced with increasing mineral oil content, due to the increase in the resistivity of the paste. However, when only $20 \%$ of mineral oil is used the intensity of $\mathrm{I}_{\mathrm{pa}}$ is also reduced, since in this case the excessive reduction in the amount of binder causes uneven packing of the carbon paste inside the work electrode. As a result, the mass ratio of $75: 25(\% \mathrm{~m} / \mathrm{m}$, grafite:mineral oil) was selected to be used in the following steps of this investigation.

Table 1. Influence of electrode composition (grafite:mineral oil mass ratio) on the voltammetric response of OXA

\begin{tabular}{lccc}
\hline & \multicolumn{3}{c}{ Ratio / $(\% \mathrm{~m} / \mathrm{m})$} \\
\cline { 2 - 4 } & $70: 30$ & $75: 25$ & $80: 20$ \\
\hline $\mathrm{I}_{\mathrm{pa}} / \mu \mathrm{A}$ & $294.4 \pm 8.7$ & $343.1 \pm 7.9$ & $288.5 \pm 9.1$ \\
$\mathrm{E}_{\mathrm{pa}} / \mathrm{V}$ & $1.140 \pm 0.002$ & $1.136 \pm 0.001$ & $1.137 \pm 0.001$ \\
$\mathrm{~W}_{1 / 2} / \mathrm{V}$ & $0.110 \pm 0.006$ & $0.113 \pm 0.005$ & $0.112 \pm 0.006$ \\
\hline
\end{tabular}

$\mathrm{I}_{\mathrm{pa}}$ : intensity of the peak current; $\mathrm{E}_{\mathrm{pa}}$ : peak potential; $\mathrm{W}_{1 / 2}$ : mid-height peak width.

The choice of the ideal analytical conditions is extremely important when intending to increase sensitivity 
and detect lower amounts of the analyte. Pulse techniques such as DPV and square wave voltammetry (SWV) provide a reduction of the capacitive current, thus generating more defined peaks and with greater intensity of peak current. This greatly increases the sensitivity of the analyses. In this work, three instrumental parameters of DPV (scan rate, pulse amplitude and pulse time) and SWV (pulse amplitude, pulse frequency and step potential) were acquired in a univariate way. The criteria defined to select the best values were: higher current peak intensity, lower deviations in $\mathrm{I}_{\mathrm{pa}}$ between repetitions, and lower $\mathrm{W}_{1 / 2}$ values. Table 2 shows the assessment interval and the best value chosen for each parameter in both techniques. With these conditions, comparison between analyses was carried out for the same OXA solution ( $50 \mathrm{mg} \mathrm{L}^{-1}$ in $\mathrm{KOH} 0.100 \mathrm{~mol} \mathrm{~L}^{-1}$ ) by DPV and SWV, as shown in Figure 5. It is suggested that DPV is the most appropriate technique, for it provided an increase in $\mathrm{I}_{\mathrm{pa}}$ of approximately $83 \mu \mathrm{A}$ and a small displacement of $\mathrm{E}_{\mathrm{pa}}$ to less positive values. Consequently, lower energy

Table 2. Voltammetric parameters of the DPV and SWV techniques applied in the analysis of OXA

\begin{tabular}{lcc}
\hline Parameter & Range of investigation & Chosen value \\
\hline DPV & $2-50$ & 20 \\
Scan rate / $\left(\mathrm{mV} \mathrm{s}^{-1}\right)$ & $5-100$ & 100 \\
Pulse amplitude / $\mathrm{mV}$ & $2-100$ & 5 \\
Pulse time / ms & & \\
\hline SWV & $10-100$ & 10 \\
Pulse amplitude / mV & $10-100$ & 75 \\
Pulse frequency / Hz & $1-10$ & 2 \\
Step potential / $\mathrm{mV}$ &
\end{tabular}

DPV: differential-pulse voltammetry; SWV: square-wave voltammetry.

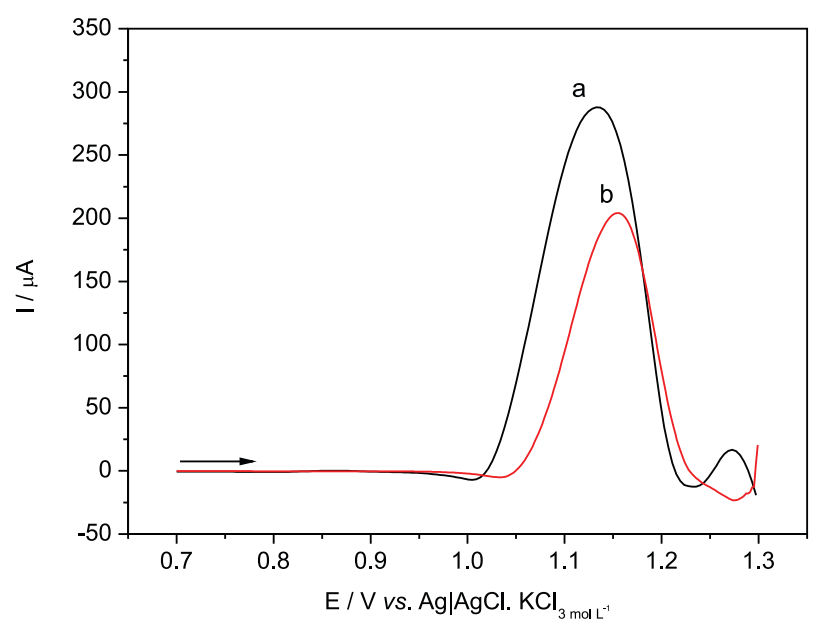

Figure 5. Voltammograms acquired under optimized conditions in (a) DPV and (b) SWV for a $50.00 \mathrm{mg} \mathrm{L}^{-1} \mathrm{OXA}$ solution in $0.100 \mathrm{~mol} \mathrm{~L}^{-1}$ $\mathrm{KOH}$ solution. requirements and higher selectivity in the analysis are effected with DPV than with SWV.

\section{Adsorptive stripping voltammetry (AdSV)}

The possibility to electrochemically pre-concentrate OXA and to enhance analytical sensitivity are the advantages of adsorptive stripping voltammetry (AdSV). This technique is based on the principle that many organic compounds can undergo physico-chemical interactions that favor their adsorption in the solid state, thereby enabling determination of the species after its accumulation on the surface of the work electrode in contact with the solution. ${ }^{38}$

Two steps were followed in this procedure: first, an electrical potential close to the $\mathrm{E}_{\mathrm{pa}}$ value registered by OXA was applied for a specific time interval. This step corresponds to the deposition of the analyte under magnetic stirring at $300 \mathrm{rpm}$, during which the target compound is electrochemically accumulated close to the electrical double layer on the surface of the work electrode. In the following step, the DPV scanning was performed within the electrical potential range that corresponds to OXA oxidation.

In this assay, the best electrical potential $\left(\mathrm{E}_{\mathrm{D}}\right)$ was initially examined to be applied in the deposition step. By considering the characteristic OXA oxidation peak without any pre-concentration, $\mathrm{E}_{\mathrm{D}}$ values were assessed before, during and after $(+1.05,+1.12$ and $+1.18 \mathrm{~V}$ versus $\mathrm{Ag} \mid \mathrm{AgCl}$, $\mathrm{KCl} 3 \mathrm{M}$, respectively) the occurrence of the OXA anodic oxidation peak. Figure $6 \mathrm{~A}$ shows a comparison between the voltammograms for different $E_{D}$ values, with a displacement of $E_{p a}$ for lower energy values for all deposition potentials. This can be ascribed to the fact that the electrochemical deposition phenomenon enhances the OXA mass transfer to the surface of the work electrode. It can also be inferred that $\mathrm{I}_{\mathrm{pa}}$ increases for all deposition potentials, although such increment is less significant for the two highest potentials. Such behavior suggests that the application of higher electrical potentials causes passivation of the electrode surface and, therefore, the intensity of the peak current is reduced. With a fixed $E_{D}$ value of $+1.05 \mathrm{~V}$, the duration of the deposition step $\left(t_{\mathrm{D}}\right)$ was assessed, and the $\mathrm{I}_{\mathrm{pa}}$ values obtained when $t_{D}$ varies between 30 and $120 \mathrm{~s}$ are shown in Figure 6B. It can be seen that $\mathrm{I}_{\mathrm{pa}}$ increases up to $45 \mathrm{~s}$ of $E_{D}$ application, after which it decreases continuously. From these results, the step of electrochemical pre-concentration was promoted in all subsequent analyses, with $\mathrm{E}_{\mathrm{D}}=+1.05 \mathrm{~V}$ for $45 \mathrm{~s}$ immediately before each voltammetric scan.

\section{Voltammetric methodology and analytical curves}

As already discussed, since the DPV technique was 

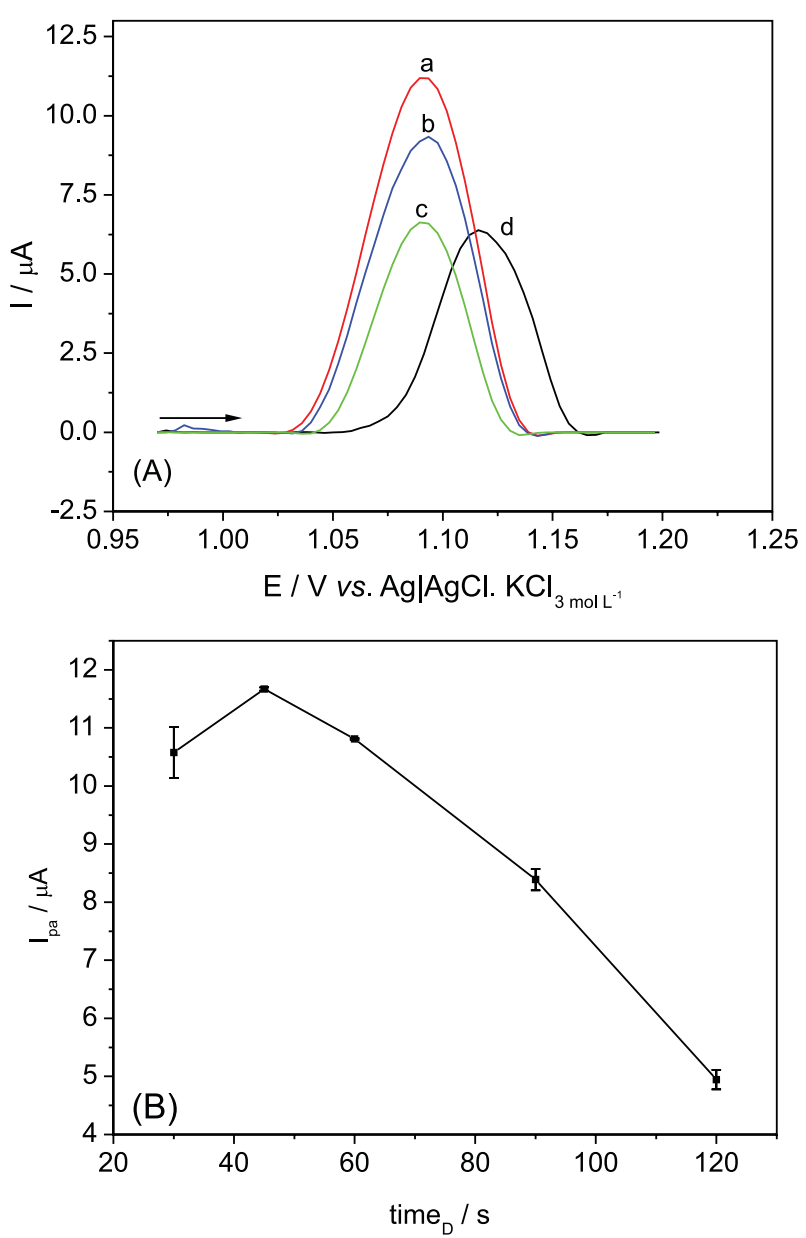

Figure 6. (A) Voltammograms in DPV for different deposition potentials: (a) +1.05 V; (b) +1.12 V; (c) +1.18 V; (d) without deposition; (B) effect of deposition time on the peak current for a $50.00 \mathrm{mg} \mathrm{L}^{-1}$ OXA solution in $0.100 \mathrm{~mol} \mathrm{~L}^{-1} \mathrm{KOH}$ solution $\left(\mathrm{E}_{\mathrm{D}}=+1.05 \mathrm{~V}\right)$.

carried out under optimized conditions with the best parameters, the voltammograms were acquired with higher peak current intensity, lower anodic peak potential and better repeatability than SWV for the analysis of a $50.00 \mathrm{mg} \mathrm{L}^{-1}$ OXA solution. Also, OXA solutions were prepared by diluting the stock solution of the analyte in order to prepare different samples with concentrations ranging between 0.500 and $40.00 \mathrm{mg} \mathrm{L}^{-1}$.

Then, by applying the AdSV technique proposed in this work, analytical curves ( $\mathrm{I}_{\mathrm{pa}}$ versus OXA concentration) were plotted with the method of least squares with or without matrix, in order to examine the matrix effect. Figure 7 shows the voltammograms in DPV for OXA solutions in different concentrations in the absence of matrix (Figure 7A) and in the pond samples (Figure 7B). In each assay, $9.00 \mathrm{~mL}$ of pond water were added to a proper amount of OXA stock solution together with the supporting electrolyte ( $\left.\mathrm{KOH} 0.100 \mathrm{~mol} \mathrm{~L}^{-1}\right)$ to construct analytical curves for an OXA concentration range within 2.00 and $40.00 \mathrm{mg} \mathrm{L}^{-1}$. The analytical curves constructed in the absence of matrix and in the presence of pond water samples, which were shown as inserts in Figures 7A and 7B, are better compared in Table 3. It can be seen that only a small matrix effect is indicated, which is confirmed by the slightly lower sensitivity (slope) of the analytical curve that corresponds to pond water samples. Such lower sensitivity was the main reason for which the concentration range applied in this study was narrowed, since the repeatability of the $\mathrm{I}_{\mathrm{pa}}$ measurements for samples with concentrations below $2.00 \mathrm{mg} \mathrm{L}^{-1}$ was impaired.
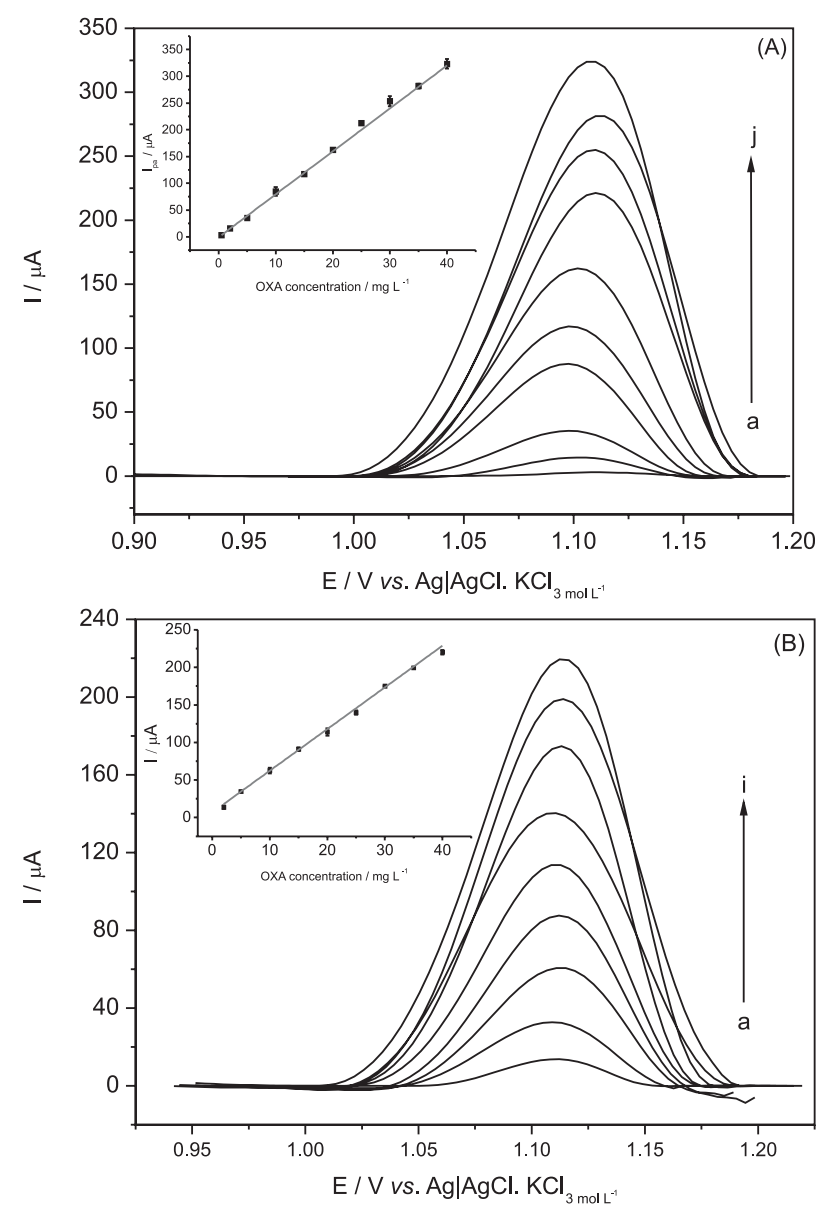

Figure 7. (A) Voltammograms in DPV for OXA concentrations: (a) 0.500 ; (b) 2.00; (c) 5.00; (d) 10.00; (e) 15.00; (f) 20.00; (g) 25.00; (h) 30.00; (i) 35.00 ; (j) $40.00 \mathrm{mg} \mathrm{L}^{-1}$, in the absence of matrix (insert: variation of $\mathrm{I}_{\mathrm{pa}}$ with OXA concentration); (B) voltammograms in DPV for OXA concentrations: (a) 2.00; (b) 5.00; (c) 10.00; (d) 15.00; (e) 20.00; (f) 25.00; (g) 30.00 ; (h) 35.00 ; (i) $40.00 \mathrm{mg} \mathrm{L}^{-1}$, in the pond samples (insert: variation of $\mathrm{I}_{\mathrm{pa}}$ with OXA concentration).

Table 3 shows the linear equations of the best-fit analytical curves, together with the limits of detection (LOD) and quantification (LOQ) calculated in the absence and presence of matrix. The LOD and LOQ values for OXA were calculated with equations 2 and $3,{ }^{39}$ where $S_{b}$ is the absolute standard deviation of the electrical current measured exactly at the $\mathrm{E}_{\mathrm{pa}}$ of the analyte in 12 scans carried 
Table 3. Linear regression, detection and quantification limits for OXA analyses

\begin{tabular}{lcccccc}
\hline Matrix & Linear equation & $\mathrm{R}^{2}$ & $\mathrm{LOD} /\left(\mathrm{mg} \mathrm{L}^{-1}\right)$ & $\mathrm{LOD} /\left(\mu \mathrm{mol} \mathrm{L}^{-1}\right)$ & $\mathrm{LOQ} /\left(\mathrm{mg} \mathrm{L}^{-1}\right)$ & $\mathrm{LOQ} /\left(\mu \mathrm{mol} \mathrm{L}^{-1}\right)$ \\
\hline Absent & $\mathrm{I}_{\mathrm{pa}}(\mu \mathrm{A})=8.03\left[\mathrm{C}\left(\mathrm{mg} \mathrm{L}^{-1}\right)\right]-0.987$ & 0.998 & 0.0570 & 0.218 & 0.192 & 0.735 \\
Pond water & $\mathrm{I}_{\mathrm{pa}}(\mu \mathrm{A})=5.55\left[\mathrm{C}\left(\mathrm{mg} \mathrm{L}^{-1}\right)\right]+6.76$ & 0.998 & 0.386 & 1.48 & 1.29 & 4.94 \\
\hline
\end{tabular}

$\mathrm{R}^{2}$ : coefficient of determination; LOD: limit of detection; LOQ: limit of quantification.

out in blank, and b is the slope of the analytical curve, with a confidence level of $95 \%(n=12){ }^{40}$

$$
\begin{aligned}
& \mathrm{LOD}=\frac{3 \times \mathrm{S}_{\mathrm{b}}}{\mathrm{b}} \\
& \mathrm{LOQ}=\frac{10 \times \mathrm{S}_{\mathrm{b}}}{\mathrm{b}}
\end{aligned}
$$

\section{Validation of the electroanalytical method}

The determination of accuracy and applicability of the method devised in this work was performed with real water samples collected from the lakes and ponds in the main campus of the Federal University of Viçosa (UFV, Viçosa, Brazil). DPV scans performed with samples containing only pond water and $\mathrm{KOH} 0.100 \mathrm{~mol} \mathrm{~L}^{-1}$ did not show any anodic peak within the OXA oxidation range, which is an evidence that the antibiotic was not found in the collected samples.

This induced the implementation of apparent OXA recovery assays, whereby aliquots of the water samples were intentionally contaminated with different amounts of OXA, namely 2.00, 20.00 and $40.00 \mathrm{mg} \mathrm{L}^{-1}$, all within the concentration range of the analytical curve constructed for samples in the presence of matrix. Then, four $20 \mu \mathrm{L}$ ( $1^{\text {st }}$ sample) or $50 \mu \mathrm{L}\left(2^{\text {nd }}\right.$ and $3^{\text {rd }}$ samples $)$ aliquots of the OXA stock solution were added to each contaminated sample. The concentration of the initial contamination was therefore estimated by the linear regression equation obtained from the four OXA additions followed after each contaminated sample. The apparent recovery rate was determined in each assay by the percentage relationship between the estimated and actual concentrations of OXA in the samples. Table 4 shows the apparent recovery rates for all three investigated concentrations, ranging between
98.4 and $109 \%$. In the literature, it is suggested that values between 70 and $120 \%$ are required in order to validate the method with real water samples. ${ }^{41}$

Other validation parameters for the proposed method, particularly the repeatability and intermediary precision, were also examined by calculating the relative standard deviation (RSD) between the repetitions of the voltammetric measurements. The repeatability is associated with measurements of a single samples in different solutions $(\mathrm{n}=7)$ prepared in the same day, and the intermediary precision is applied for repetitions between solutions $(\mathrm{n}=5)$ prepared in different days. The devised method showed maximal RSD's of 4.68 and $7.85 \%$ for repeatability and intermediary precision, respectively, which are in accordance with what is prescribed by MAPA (Brazilian Department for Agriculture, Livestock and Supplies). ${ }^{42}$

\section{Conclusions}

A novel electrochemical method which is rapid, cheap and efficient for the analysis of the antibiotic oxolinic acid (OXA) was successfully developed and implemented in its determination in aqueous samples. The electrochemical characterization of OXA was carried out by cyclic voltammetry in a $0.100 \mathrm{~mol} \mathrm{~L}^{-1} \mathrm{KOH}$ solution as supporting electrolyte, showing an anodic peak at approximately $+1.15 \mathrm{~V}$, which is typical of an irreversible oxidation process effected with the transfer of one electron on the surface of a carbon paste electrode. Differential-pulse voltammetry coupled with an adsorptive pre-concentration step proved to be the most sensitive technique for the detection of OXA at concentrations up to $0.0572 \mathrm{mg} \mathrm{L}^{-1}$ (LOD), with good linearity, repeatability and precision. The method was applied to quantify OXA in water samples from lakes and ponds in the campus of Federal University

Table 4. Results of the apparent recovery analyses for different OXA concentrations

\begin{tabular}{lcccc}
\hline $\begin{array}{l}\text { Added concentration / } \\
\left(\mathrm{mg} \mathrm{L}^{-1}\right)\end{array}$ & $\begin{array}{c}\text { Acquired concentration / } \\
\left(\mathrm{mg} \mathrm{L}^{-1}\right)\end{array}$ & Apparent recovery / \% & Repeatability / \% & Reproducibility / \% \\
\hline 2.000 & 2.181 & 109 & 4.68 & 7.85 \\
20.00 & 19.67 & 98.4 & 4.46 & 6.44 \\
40.00 & 39.83 & 99.6 & 1.20 & 4.38 \\
\hline
\end{tabular}

RSD: relative standard deviation. 
of Viçosa (Brazil). The accuracy was good, as confirmed by the method of apparent recovery of a sample that was intentionally contaminated with the analyte, which demonstrates the capacity of the method to be applied with real samples. The results incite the development of a chemically-modified electrode with the purpose of reducing the limits of detection and quantification, as well as a study to investigate the application of this sensor as a viable alternative to determine OXA in other matrices.

\section{Acknowledgments}

The authors are grateful to Brazilian research funding agencies CNPq (process No. 440382/2014-9), CAPES and FAPEMIG for financial support.

\section{References}

1. Regitano, J. B.; Leal, R. M. P.; Rev. Bras. Cienc. Solo 2010, 34, 601.

2. Aerts, M. M. L.; Hogenboom, A. C.; Brinkman, U. A. T.; J. Chromatogr. B 1995, 667, 1.

3. Boxall, A. B. A.; Fogg, L.; Blackwell, P. A.; Kay, P.; Pemberton, E. J.; Review Of Veterinary Medicines in the Environment; Environment Agency, Bristol, 2002. Available at https://www. gov.uk/government/uploads/system/uploads/attachment_data/ file/290328/sp6-012-8-tr-e-e.pdf, accessed in December 2017.

4. Cardoso, L. V.; Tomasini, D.; Sampaio, M. R. F.; Caldas, S. S.; Kleemann, N.; Primel, E. G.; Gonçalves, F. F.; J. Braz. Chem. Soc. 2011, 22, 1944.

5. Alexy, R.; Schöll, A.; Kümpel, T.; Kümmerer, K.; Pharmaceuticals in the Environment, $2^{\text {nd }}$ ed.; Kümmerer, K., ed.; Springer-Verlag: Berlim, 2004, p. 209.

6. Thiele-Bruhn, S.; J. Plant Nutr. Soil Sci. 2003, 166, 145.

7. Gastalho, S.; da Silva, G. J.; Ramos, F.; Acta Farm. Port. 2014, 3,29 .

8. Prola, L. D. T.; Buriol, L.; Frizzo, C. P.; Caleffi, G. S.; Marzari, M. R. B.; Moreira, D. N.; Bonacorso, H. G.; Zanatta, N.; Martins, M. A. P.; J. Braz. Chem. Soc. 2012, 23, 1663.

9. Faria, A. F.; Souza, M. V. N.; Oliveira, M. A. L.; J. Braz. Chem. Soc. 2008, 19, 389.

10. Andriole, V. T.; Clin. Infect. Dis. 2005, 41 (Supplement 2), S113.

11. Oliphant, C. M.; Green, G. M.; Am. Fam. Physician 2002, 65 , 455.

12. Ziganshina, L. E.; Squire, S. B.; Cochrane Database Syst. Rev. 2008, 1, 1. DOI 10.1002/14651858.CD004795.pub3.

13. Vree, T. B.; Van Ewijk-Beneken Kolmer, E. W. J.; Nouws, J. F. M.; J. Chromatogr. B: Biomed. Sci. Appl. 1992, 579, 131.

14. Guyonnet, J.; Pacoud, M.; Richard, M.; Doisi, A.; Spavone, F.; Hellings, Ph.; J. Chromatogr. B: Biomed. Sci. Appl. 1996, 679, 177.
15. da Silva, J. M. B.; Hollenbach, C. B.; Arq. Inst. Biol. 2010, 77, 363.

16. Silva, E. N.; Duarte. A.; Rev. Bras. Cienc. Avic. 2002, 4, 85.

17. Bjiirklund, H. V.; Rpbergh, C. M. I.; Bylund, G.; Aquaculture 1990, 97, 85 .

18. Capitán-Vallvey, L. F.; Al-Barbarawi, O. M. A.; FernándezRamos, M. D.; Avidad, R.; Talanta 2013, 60, 247.

19. Ministério da Agricultura Pecuária e Abastecimento (MAPA); Instrução Normativa No. 09, Brasília, 2017. Avaliable at www. agricultura.gov.br/assuntos/inspecao/produtos-animal/plano-denacional-de-controle-de-residuos-e-contaminantes/documentosda-pncrc/pncrc-2017.pdf, accessed in August, 2017.

20. Takatsuki, K.; J. Chromatogr. A 1991, 538, 259.

21. Pfenning, A. P.; Munns, R. K.; Turnipseed, S. B.; Roybal, J. E.; Holland, D. G.; Long, A. R.; J. AOAC Int. 1996, 79, 1227.

22. Yánez-Jácome, G. S.; Aguilar-Caballos, M. P.; Gómez-Hens, A.; J. Chromatogr. A 2015, 1405, 126.

23. Díaz, R. C. R.; Romero, J. M. F.; Caballos, M. P. A.; Hens, A. G.; J. Agric. Food Chem. 2006, 54, 9670.

24. Castillo-García, M. L.; Aguilar-Caballos, M. P.; Gómez-Hens, A.; J. Chromatogr. A 2015, 1425, 73.

25. Agüí, M. L.; Campaña, A. M. G.; Blanco, C. C.; Gracia, L. G.; Food Control 2015, 50, 864.

26. Rocha, D. G.; Santos, F. A.; da Silva, J. C. C.; Augusti, R.; Faria, A. F.; J. Chromatogr. A 2015, 1379, 83.

27. Herrera-Herrera, A. V.; Hernández-Borges, J.; Borges-Miquel, T. M.; Rodríguez-Delgado, M. A.; J. Pharm. Biomed. Anal. 2013, 75, 130.

28. Prat, M. D.; Benito, R.; Compañó, J.; Hernández-Arteseros, J. A.; Granados, M.; J. Chromatogr. A 2004, 1041, 27.

29. Herrera-Herrera, A. V.; Ravelo-Pérez, L. M.; Hernández-Borges, J.; Afonso, M. M.; Palenzuela, J. A.; Rodríguez-Delgado, M. A.; J. Chromatogr. A 2011, 1218, 5352.

30. Barrón, D.; Jiménez-Lozano, E.; Bailac, S.; Barbosa, J.; Anal. Chim. Acta 2003, 477, 21.

31. Merás, I. D.; de la Peña, A. M.; López, F. S.; Cáceres, M. I. R.; Analyst 2000, 125, 1471.

32. Galli, A.; de Souza, D.; Garbelini, G. S.; Coutinho, C. F. B.; Mazo, L. H.; Avaca, L. A.; Quim. Nova 2006, 29, 105.

33. Nicholson, R. S.; Shain, I.; Anal. Chem. 1964, 36, 706.

34. Brett, C. M. A.; Brett, A. M. O.; Electrochemistry: Principles, Methods and Applications; Oxford University Press: New York, 1993, p. 444.

35. Veterinary Substances DataBase, University of Hertfordshire, UK, available at http://sitem.herts.ac.uk/aeru/vsdb/ Reports/1879.htm, accessed in October, 2017.

36. Tanaka, H.; Kuroboshi, M.; Tori, S. In Organic Electrochemistry, Revised and Expanded, $5^{\text {th }}$ ed.; Hammerich, O.; Speiser, B., eds.; CRC Press: London, UK, 2016, p. 1268.

37. Garrido, E. M. P. J.; Garrido, J. M. P. J.; Milhazes, N.; Borges, F.; Oliveira-Brett, A. M.; Bioelectrochemistry 2010, 79, 77. 
38. Kalvoda, R.; Kopanica, M.; Pure Appl. Chem. 1989, 61, 97.

39. International Union of Pure Applied Chemistry (IUPAC); Spectrochim. Acta 1978, 33B, 241.

40. Miller, J. C.; Miller, J. N. In Statistics for Analytical Chemistry, $2^{\text {nd }}$ ed.; Ellis Horwood Limited Publication: Chichester, 1984, p. 233.

41. Ribani, M.; Botolli, C. B. G.; Collins, C. H.; Jardim, I. C. S. F.; Melo, L. F. C.; Quim. Nova 2004, 27, 771.
42. Ministério da Agricultura Pecuária e Abastecimento (MAPA); Manual de Garantia da Qualidade Analítica; MAPA: Brasília, 2011, p. 40.

Submitted: November 8, 2017 Published online: January 12, 2018 